\title{
APLICAÇÃO DO ELETROFOTÔMETRO DE FISHER Á DOSAGEM DE TIAMINA
}

\section{O. F. Ribeiro e Lucia Aché}

A determinação quantitativa de tiamina por intermédio da reação de Prebluda e McCollum se faz normalmente pela comparação colorimétrica ou pelo espectro-fotometro. No primeiro destes casos as leituras estão sujeitas aos erros habituais da colorimetria, erros que, no mais das vezes, não são despreziveis; pelo espectro-fotometro o resultado é preciso, mas tal aparelho não é facilmente accessivel a todos os laboratórios; daí o termos procurado adaptar a leitura da côr desenvolvida pela tiamina na reação de Prebluda e McCollum à célula fotoeletrica, de maior precisão que o colorimetro e de custo muito inferior ao do espectro-fotometro.

Utilizamos, para o traçado da curva, soluções de cloridrato de tiamina em quantidades variáveis de $10 \%$ por $\mathrm{cm}^{3}$ e a partir de 0 até 200\%. adotando a reação modificada por Auerbach. (Journal of the American Pharmaceutical Association, 1940 - 29, 313-15).

De início verificamos que apenas a partir de $30 \mu$ por $\mathrm{cm}^{3}$ o desenvolvimento de côr podia permitir uma leitura corréta de acôrdo com a curva traçada, utilizando uma célula fotoeletrica de modelo Fisher. Como unica modificação no método adotado, uma vez completada a reação, juntavamos alcool etilitico a $96^{\circ}$ até um volume de $25 \mathrm{~cm}^{3}$.

Em séries de escalas, repetidas varias vezes afim de comprovar a reprodutividade dos resultados, verificamos que com a técnica de Auerbach não é sempre concordante a leitura da côr desenvolvida com as mesmas quantidades de tiamina, mas que para cada série de leituras obtem-se exatamente o mesmo tipo de curva; assim não é possível para a dosagem de amostras desconhecidas, prescindir de um padrão que sirva de ponto de referência. Para a leitura precisa importa que se faça pois um padrão com quantidade conhecida de tiamina o qual substituiria o "blank" na leitura do desconhecido.

Assim, por exemplo, para adotar a curva tal como a obtivemos em nosso aparelho, fazemos, juntamente com o desconhecido, um tubo padrão de 100\%. de tiamina; ao calibrar o aparelho o padrão de $100 \mu$ é 
utilizado como se fosse "blank", tendo-se o cuidado de ajustar antes a escala logarítima em 34,0 que é precisamente o ponto de nossa curva que corresponde à quantidade de $100 \mu$ de tiamina. Ajustado assim o padrão no número 34,0 da escala logarítima procede-se como de hábito para a leitura do desconhecido e a cifra encontrada se transporta diretamente para a curva. Com este simples artifício os resultados obtidos não acusam erros maiores que $1 \%$.

\section{RESUMO}

Utilizando o eletrofotômetro de Fisher para a dosagem da tiamina foi verificado ser necessária a feitura concomitante de um tubo padrão o qual deve ser utilizado como si fosse o "blank". As dosagens realizadas pelo eletrofotômetro, com quantidades de tiamina variando de 30 a 200 gamas por $\mathrm{cm}^{3}$ não mostram erros superiores a $1 \%$.

\section{SUMMARY}

Utilizing the Fisher electrophotometer for the dosing of tiamin it was thereby verified to be necessary the concomitant fact of a standard tube wich must be utilized as if it were the blank. The dosings realized by the electrophotometer with a quantity of tiamim, varying from 30 to $200 \%$ by $\mathrm{ml}$ do not show errors higher than one per cent. 


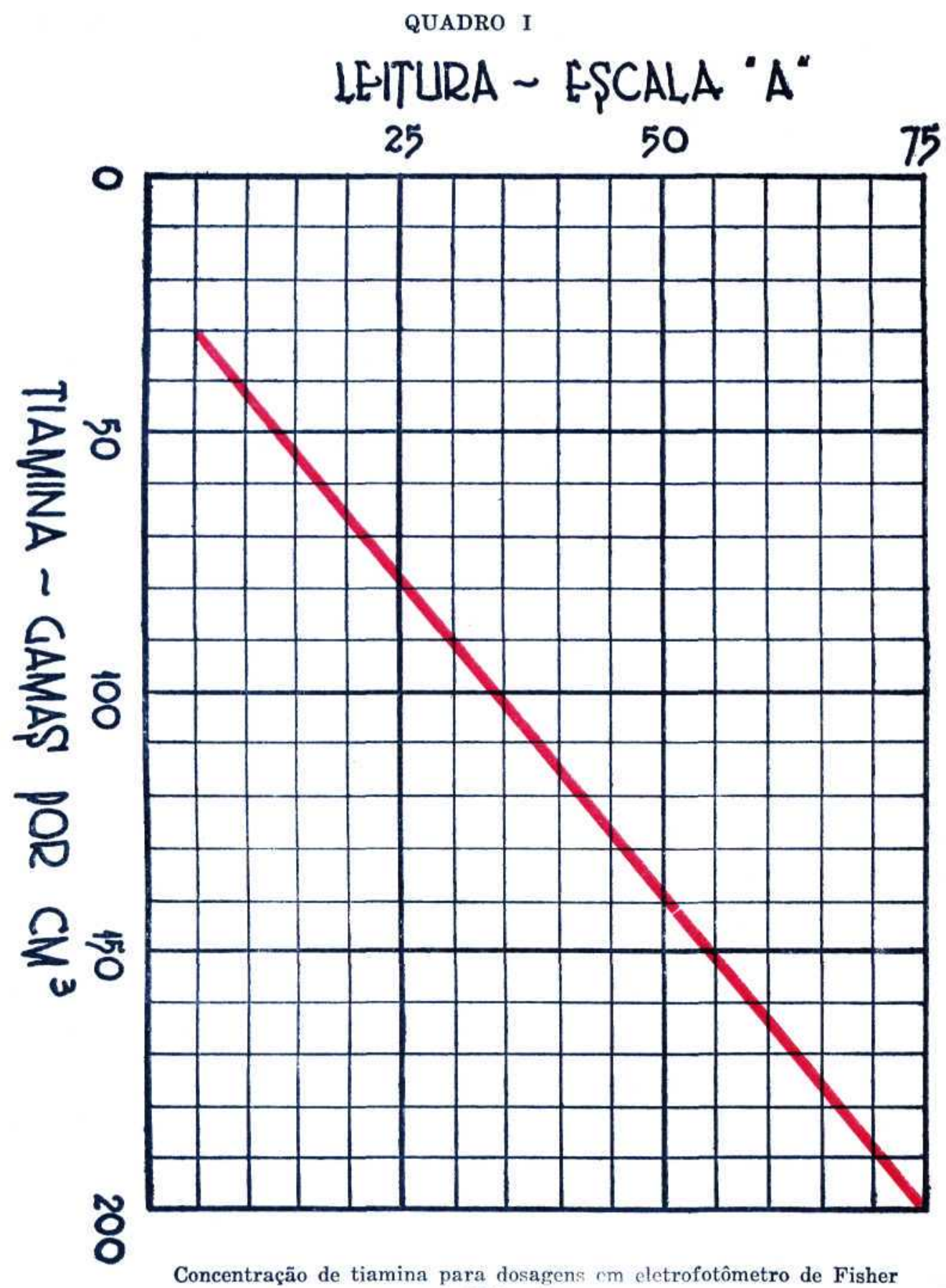

(Filtro B 525) 